\title{
CLB5 and CLB6 are required for premeiotic DNA replication and activation of the meiotic S/M checkpoint
}

\author{
David Stuart ${ }^{1}$ and Curt Wittenberg ${ }^{1-3}$ \\ Departments of Molecular Biology ${ }^{1}$ and Cell Biology², The Scripps Research Institute, La Jolla, California 92037 USA
}

\begin{abstract}
Initiation of DNA replication during the mitotic cell cycle requires the activation of a cyclin-dependent protein kinase (CDK). The B-type cyclins $\mathrm{Cl}$ b5 and Clb6 are the primary activators of the S phase function of the budding yeast CDK Cdc28. However, in mitotical ly growing cells this role can be fulfilled by the other B-type cyclins Clb1-Clb4. We report here that cells undergoing meiotic development also require Clb dependent CDK activity for DNA replication. Diploid clb5/clb5 clb6/clb6 mutants are unable to perform premeiotic DNA replication. Despite this defect, the mutant cells progress into the meiotic program and undergo lethal segregation of unreplicated DNA suggesting that they fail to activate a checkpoint that restrains meiotic $M$ phase until DNA replication is complete. We have found that a DNA replication checkpoint dependent on the ATM homolog MEC 1 operates in wild-type cells during meiosis and can be invoked in response to inhibition of DNA synthesis. Although cells that lack clb5 and clb6 are unable to activate the meiotic DNA replication checkpoint, they do possess an intact DNA damage checkpoint which can restrain chromosome segregation in the face of DNA damage. We conclude that C LB5 and CLB6 are essential for premeiotic DNA replication and, consequently, for activation of a meiotic DNA replication checkpoint.
\end{abstract}

[Key Words: CLB; cyclin; CDK; meiosis; DNA replication; checkpoint]

Received May 28,1998; revised version accepted July 8, 1998.

The eukaryotic cell cycle consists of a highly orchestrated series of events that al low the faithful duplication of chromosomes and cellular constituents and promotes their accurate segregation to produce two nearly identical daughter cells (Lew et al. 1997). Maintenance of cell cycle organization is the result of the combined effect of dependent events and cell cycle checkpoints (Hartwell 1974; Hartwell and Weinert 1989). However, our increasing understanding of cell cycle regulation during development is revealing that, despite the stringent requirement for the fidelity of the processes that comprise the cell cycle, the organization of cell cycle events and the duration of cell cycle phases are actually quite mall eable (N ewport and Kirschner 1984; O'Farrell et al . 1989; Edgar et al. 1994; Orr-Weaver 1994). Of the numerous examples of al tered cell cycle organization shown to occur in metazoans during devel opment, those occurring during gametogenesis are among the most dramatic (OrrWeaver 1994; Su et al. 1998). The process of generating haploid gametes from diploid somatic cells through meiosis involves the dramatic reorganization of cell

${ }^{3}$ Corresponding author.

E-MAIL curtw@scripps.edu; FAX (619) 784-2265. cycle phases. Dipl oid cells undergo a round of premeiotic DN A replication followed by two rounds of chromosome segregation without an intervening $S$ phase. Furthermore, substantial alterations in chromatin organization and chromosome dynamics occur during the process of haploidization (McKim and Hawley 1995; Kleckner 1996; Roeder 1997). Although these substantial differences have been recognized for many years, the cell cycle regulatory events that govern them are just beginning to be elucidated. Although the specifics are unclear, it is clear that changes of this magnitude will involve differences both in the implementation of the cell cycle regulatory machinery and in the nature and utilization of cell cycle checkpoints.

Cell cycle organization can be attributed to the pattern of activation of the cell cycle regulatory machinery, the cyclin-dependent protein kinases (CDKs). CDKs, along with their positive regulatory subunits, the cyclins, govern progression through the major transitions of the mitotic cell cycle (Reed 1992; N asmyth 1993). In the budding yeast, these roles can be attributed to a single CDK, Cdc28. The Cdc28 CDK is activated by at least nine distinct cyclins, three $\mathrm{G}_{1}$ cyclins and six B-type cyclins (Nasmyth 1993). The $\mathrm{G}_{1}$ cyclins, CLN1, CLN2, and 
CLN3, are essential for cell cycle initiation during $G_{1}$ phase (Richardson et al . 1989). Two of the B-type cyclins, CLB5 and CLB6, promote the transition from $\mathrm{G}_{1}$ into $\mathrm{S}$ phase (Epstein and Cross 1992; Kuhne and Linder 1993; Schwob and Nasmyth 1993), whereas the remaining four, CLB1-CLB4, promote events required for the completion of mitosis (Fitch et al. 1992; Richardson et al. 1992). Substantial functional redundancy exists with both $G_{1}$ and B-type cyclin subclasses such that elimination of one or more members of a class has only limited effects on the kinetics of cell cycle progression (Richardson et al. 1989, 1992; Fitch et al. 1992). For example, although it is assumed that CLB5 and CLB6 are the physiologically relevant activators of the $S$ phase function of the Cdc28 CDK, their inactivation results in only a modest delay in initiation of DNA replication (Epstein and Cross 1992; Kuhne and Linder 1993; Schwob and $\mathrm{N}$ asmyth 1993). That this results from functional redundancy with CLB1-CLB4 is demonstrated by the fact that inactivation of all six B-type cyclins leads to an absolute block in DN A replication (Schwob et al. 1994).

The importance of CDKs in progression through meiosis is well documented. Some of the earliest studies of cell cycle control in eukaryotes were performed with prophase-arrested amphibian and invertebrate oocytes in which it was found that progression into the first meiotic division was dependent on an activity called maturation promoting factor (MPF) (M asui and M arkert 1971). This regulatory factor was subsequently shown to consist of the CDK, Cdc2, and an associated B-type cyclin (Dunphy et al. 1988; Gautier et al. 1988, 1990; Lohka et al. 1988). B-type cyclins are also required for progression through meiotic $M$ phase in both budding yeast and fission yeast (Grandin and Reed 1993; Dahmann and Futcher 1995; lino et al. 1995). In budding yeast, CLB1, CLB3, and CLB4 are important for progression from pachytene into the first meiotic division (MI) and essential for progression from MI to MII (Dahmann and Futcher 1995). During meiosis, expression of five of the six budding yeast B type cyclins is largely controlled by the meiosis-specific transcription factor, NDT80 (Chu and Herskowitz 1998). CLB2, lacks $\mathrm{N}$ dt80 binding sites and is not expressed significantly during meiosis (Grandin and Reed 1993; Chu and Herskowitz 1998). Consistent with their role in formation and elongation of the spindle during both mitosis and meiosis (Fitch et al. 1992; Dahmann and Futcher 1995), CLB1, CLB3, and CLB4 transcripts, protein, and associated kinase activity all peak about the time of initiation of $\mathrm{MI}$ and persist until MII is complete (Grandin and Reed 1993; Chu and Herskowitz 1998). Like those cyclins, which it controls, NDT80 is also required for the pachytene to MI transition (Xu et al. 1995).

Premeiotic S phase, like the meiotic $M$ phases, bears many similarities to its counterpart in the mitotic cell cycle. Many of the same gene products required for DN A repl ication during the mitotic cycle are al so essential for meiosis. These include enzymes involved in the synthesis of DNA precursors (TMP1, RNR1, and CDC8) and in the process of replication itself (CDC2, CDC17, and
CDC9) (Simchen et al. 1976; Zamb and Roth 1977; Schild and Byers 1978; Johnson et al. 1982; Budd et al. 1989). In addition, it has been established that the same replication origins are used in both meiotic and mitotic $\mathrm{S}$ phases (Collins and N ewlon 1994). Thus, it is curious that, in contrast to their essential role in replication during the mitotic cell cycle, experiments using temperature-sensitive mutants of CDC7 and CDC28 suggest that neither is required for premeiotic DN A replication (Schild and Byers 1978; Shuster and Byers 1989). In contrast, inactivation of the Schizosaccharomyces pombe CDK, cdc2, prevents premeiotic S phase (lino et al. 1995). Despite the fact that $S$ phase of the mitotic cell cycle and meiosis share many features, substantial differences also exist as illustrated by the dependence of premeiotic S phase on a series of gene functions expressed uniquely during meiosis (Kupiec et al. 1997).

In this study, we establish that in meiosis, as in the mitotic cell cycle, CLB5 and CLB6 promote progression into premeiotic $S$ phase. However, unlike their S phase role during the mitotic cycle, their role during premeiotic $S$ phase is essential. We show that premeiotic $S$ phase is inhibited by the $\mathrm{Clb} / \mathrm{Cdc} 28$-specific CDK inhibitor, Sic1, suggesting that the essential role of Clb5 and $\mathrm{Cl}$ b6 is executed in conjunction with $\mathrm{Cdc} 28$. Despite their failure to replicate DN A, clb5/clb5 cl b6/clb6 mutants proceed into the meiotic program and undergo one or more meiotic $M$ phases. Meiotic progression in the

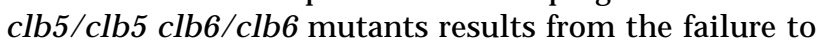
activate a MEC1-dependent DNA replication checkpoint, which we show to be operable in meiotic cells but inoperable when those cells lack CLB5 and CLB6. This study provides the first evidence of an essential role for S-phase cyclins that is distinct from those promoted by CLB1-CLB4. In addition, it provides support for the evolving perception that both the nature and regulation of some checkpoints is conserved between meiosis and mitosis.

\section{Results}

The S-phase cyclins, CLB5 and CLB6, are required for meiotic development

Progression from $G_{1}$ phase into $S$ phase of the mitotic cell cycle requires the activity of three $G_{1}$ cyclins (CLNs) and two B-type cyclins, CLB5 and CLB6. Whereas deletion of all three CLNs results in a terminal arrest in which cells are unable to form a bud or to enter $\mathrm{S}$ phase, inactivation of CLB5 and CLB6 results only in a delay in initiation and slowed progression through $\mathrm{S}$ phase (Kuhne and Linder 1993; Schwob and N asmyth 1993). Surprisingly, we have found that unlike their role in the mitotic cell cycle, $G_{1}$ cyclins (CLNs) are di spensable for meiosis and sporulation (D. Stuart and C. Wittenberg, unpubl.). Their expression is rapidly repressed when cells are induced to sporulate. In contrast, CLB5 and CLB6 are essential. Inactivation of CLB5 resulted in a dramatic reduction in sporulation efficiency relative to wild-type cells (Table 1 ), a defect that had been noted 
Table 1. Sporulation frequency and viability of wild-type and CLB mutants

\begin{tabular}{|c|c|c|c|c|c|c|}
\hline Sporulation & CLB/CLB & $\mathrm{clb5} / \mathrm{clb5}$ & $\mathrm{clb6} / \mathrm{clb} 6$ & $\begin{array}{l}\mathrm{clb5} / \mathrm{clb} 5 \\
\mathrm{clb} 6 / \mathrm{cl} 66\end{array}$ & $\begin{array}{l}\text { CLB5/clb5 } \\
\text { CLB6/clb6 }\end{array}$ & $\mathrm{HU}$ \\
\hline Unsporulated & 9.0 & 94.6 & 10.5 & 96.0 & 10.2 & 100 \\
\hline Monad & 2.9 & 0.9 & 1.0 & 2.0 & 3.0 & 0 \\
\hline Dyad & 5.0 & 2.3 & 9.0 & 1.8 & 10.4 & 0 \\
\hline Triad & 16.9 & 1.6 & 18.0 & 0.2 & 12.8 & 0 \\
\hline Tetrad & 66.2 & 0.6 & 61.5 & 0.0 & 63.6 & 0 \\
\hline Spore viability ${ }^{a}$ & 99.2 & 60.0 & 98.6 & 0.0 & 97.8 & N.A. ${ }^{b}$ \\
\hline
\end{tabular}

Sporulation frequency is determined as percent cells from a total of 1000 cells counted.

a Spore viability was determined by tetrad analysis from at least 25 tetrads for all strains except clb5/clb5 clb6/clb6, which was determined by random spores analysis.

${ }^{b}$ (N .A.) N ot applicable; cells in hydroxyurea (HU) failed to sporulate.

previously but not characterized (Epstein and Cross 1992). Although deletion of CLB6 had little effect on sporulation (Table 1), this cyclin can clearly contribute to this process because inactivation of both CLB5 and CLB6 resulted in a more dramatic defect in both tetrad formation and spore viability as compared with clb5/ clb5 mutants (T able 1). No full tetrads were observed in the $\mathrm{clb5} / \mathrm{clb} 5 \mathrm{clb} 6 / \mathrm{clb} 6$ mutant, but a small number of aberrant triads, dyads, and monads were seen (Table 1). Although $\mathrm{clb5} / \mathrm{clb} 5$ mutants are severely di minished in their capacity to sporulate and form tetrads, $60 \%$ of the spores recovered were viable. In contrast, no viable spores could be recovered from the aberrant asci in cl b5/ clb5 clb6/clb6 mutant cultures (Table 1). To determine if the severe sporulation defect in clb5/clb5 and clb5/ $\mathrm{clb5} \mathrm{clb} 6 / \mathrm{clb} 6$ mutants was unique to the SK1 strain background, we examined the effect of these mutations in an independent Saccharomyces cerevisiae strain background, BF264-15Du (Richardson et al. 1989). Despite the inherent difference in sporulation efficiency and kinetics between these two strains, the effect of the clb mutations was comparable (data not shown).

clb5 and clb5 clb6 mutants are defective in premeiotic DNA synthesis

The defect in sporulation of $\mathrm{clb} 5 / \mathrm{clb} 5 \mathrm{clb} 6 / \mathrm{clb} 6 \mathrm{mu}-$ tants suggested that, like the same mutants in the mitotic cycle, they might exhibit defects in DN A replication. Whereas the precise nature of the DN A replication defect in $\mathrm{clb} 5 \mathrm{clb} 6$ mutants during the mitotic cell cycle is unclear, there is some evidence to suggest that origin firing requires activation of $\mathrm{Clb}$-associated kinase (Schwob et al. 1994; Zou and Stillman 1998). As a consequence, DNA replication is delayed in $\mathrm{clb} 5 \mathrm{clb} 6 \mathrm{mu}-$ tants until CLB1-CLB4-associated CDK activity accumulates (Schwob and Nasmyth 1993; Schwob et al. 1994). Therefore, we examined premeiotic DN A synthesis in wild-type, clb5, clb6, or clb5 clb6 homozygous mutants. Analysis of DNA content by flow cytometry demonstrated that CLB5 and CLB6 are required for efficient premeiotic DNA replication, whereas wild-type diploids completed premeiotic $S$ phase within $4 \mathrm{hr}$ subsequent to induction of sporulation (Fig. 1). DN A repli- cation in clb5/clb5 mutants was first detectable at $\sim 8 \mathrm{hr}$ and appeared to be incomplete in many cells even after $24 \mathrm{hr}$ (Fig. 1). No delay or defect in DNA replication could be detected in $\mathrm{clb} 6 / \mathrm{cl} b 6$ mutants (data not shown). However, as observed with the defect in sporulation, combining $\mathrm{clb} 5$ and $\mathrm{clb} 6$ mutations yielded a profound defect in which no premeiotic DN A replication could be detected even after $24 \mathrm{hr}$ (Fig. 1). This flow cytometric profile of DN A content is similar to that observed when wild-type diploids were treated with the DN A synthesis inhibitor hydroxyurea (HU) following induction of sporulation (data not shown). Thus, unlike the modest defect caused by these mutations in $\mathrm{S}$ phase of the mitotic cell cycle, inactivation of both CLB5 and CLB6 appears to completely block progression into premeiotic $S$ phase.

The most likely explanation for the DN A replication defect in the Clb5- and Clb6-deficient cells is that they lack the CDK activity required to activate premeiotic DN A replication. However, it was possible that mitotically growing clb5 clb6 mutants have a defect in chromosome metabolism that is subtle during mitotic

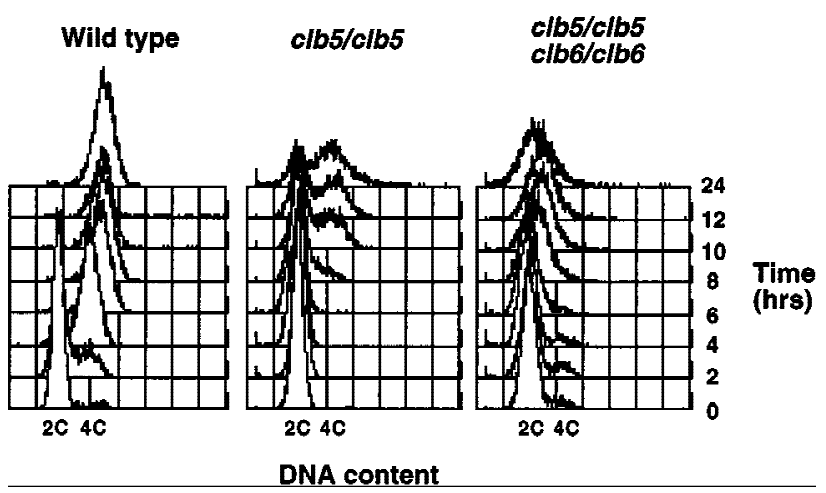

Figure 1. CLB5 and CLB6 are required for efficient premeiotic DN A replication. Synchronous populations of wild-type, clb5/ $\mathrm{clb5}$, and $\mathrm{clb5} / \mathrm{clb5} \mathrm{clb6/clb6}$ strains were isolated by centrifugal el utriation and induced to sporulate. Samples of each culture were collected every $2 \mathrm{hr}$ and DNA content of the populations was monitored by flow cytometry of propidium iodide-stained cells. The position of $2 \mathrm{C}$ and $4 \mathrm{C}$ DN A contents is indicated at the bottom of each plot. 
growth but which carries over from the final division and precludes effective premei otic DN A replication. To investigate this possibility, a clb5/clb5 clb6/clb6 GAL1CLB5 strain was grown in the presence of galactose to allow CLB5 expression. Although these cells expressed CLB5 during miti otic growth, they were unabl eto sporulate efficiently when the GAL1 promoter was repressed 1 hr prior to inducing sporulation (data not shown). Thus, the mei otic defect of clb5 clb6 mutants results specifically from the absence of $\mathrm{Cl}$ b5 and $\mathrm{Clb} 6$ during meiosis.

Clb5 accumulates during premeiotic $\mathrm{S}$ phase and activates the Cdc28 CDK

CLB5 and CLB6 RN A has been shown to accumulate at about the time that cells are undergoing premeiotic $S$ phase and peak during $\mathrm{MI}$ and $\mathrm{MII}$ (Chu and Herskowitz 1998; data not shown). Consistent with those observations, cells that have been synchronized in $G_{1}$ phase and then induced to sporulate, begin to accumulate CLB5 RNA prior to the initiation of S phase (Fig. 2A). CLB6 RNA follows the same pattern of accumulation (Chu and Herskowitz 1998). The accumulation of Clb5 protein closely follows the accumulation of mRNA with the protein abundance increasing throughout $S$ phase and reaching a peak at about the time of MI (Fig. 2B). As expected, the histone $\mathrm{H} 1$ kinase acti vity associated with $\mathrm{Cl}$ b5 also accumulates through $\mathrm{S}$ phase, reaching a peak after the completion of DNA replication (Fig. $2 \mathrm{C}$ ).

Clb5 associates with and activates the histone $\mathrm{H} 1 \mathrm{ki}$ nase activity of the Cdc28 CDK during the mitotic cell cycle and is thought to be required for its $S$ phase-promoting activity (Schwob and N asmyth 1993; Schwob et al. 1994). Clb5 is al so detected in association with Cdc28 in extracts from meiotic cells consistent with the notion that the Clb5-associated kinase activity accumulating during meiosis is Cdc28 dependent (Fig. 3A). Furthermore, when Clb5 immune complexes were prepared from cdc28-4 mutants induced to undergo meiosis and sporulation at the permissive temperature, the associated histone $\mathrm{H} 1$ kinase activity was severely diminished (Fig. 3B). It has been established previously that those mutants display little or no in vitro kinase activity even when assayed at the permissive temperature (Reed et al. 1985). However, despite the reduced levels of CIb5-associated $\mathrm{H} 1$ kinase activity measured in vitro, the cdc28-4 strain expressed $\mathrm{Cl}$ lb5 and underwent premeiotic $\mathrm{S}$ phase with similar kinetics to wild-type cells under these conditions (data not shown).

Clb-associated CDK activity is essential for premeiotic S phase

The dependence of premeiotic S phase on two B-type cyclins appeared to be at odds with the observation that $S$ phase could be completed in temperature-sensitive cdc28 mutants (Shuster and Byers 1989; Xu et al. 1997). We have independently confirmed these results (data not shown). However, such experiments are inconclusive because they could not be performed at a fully restrictive

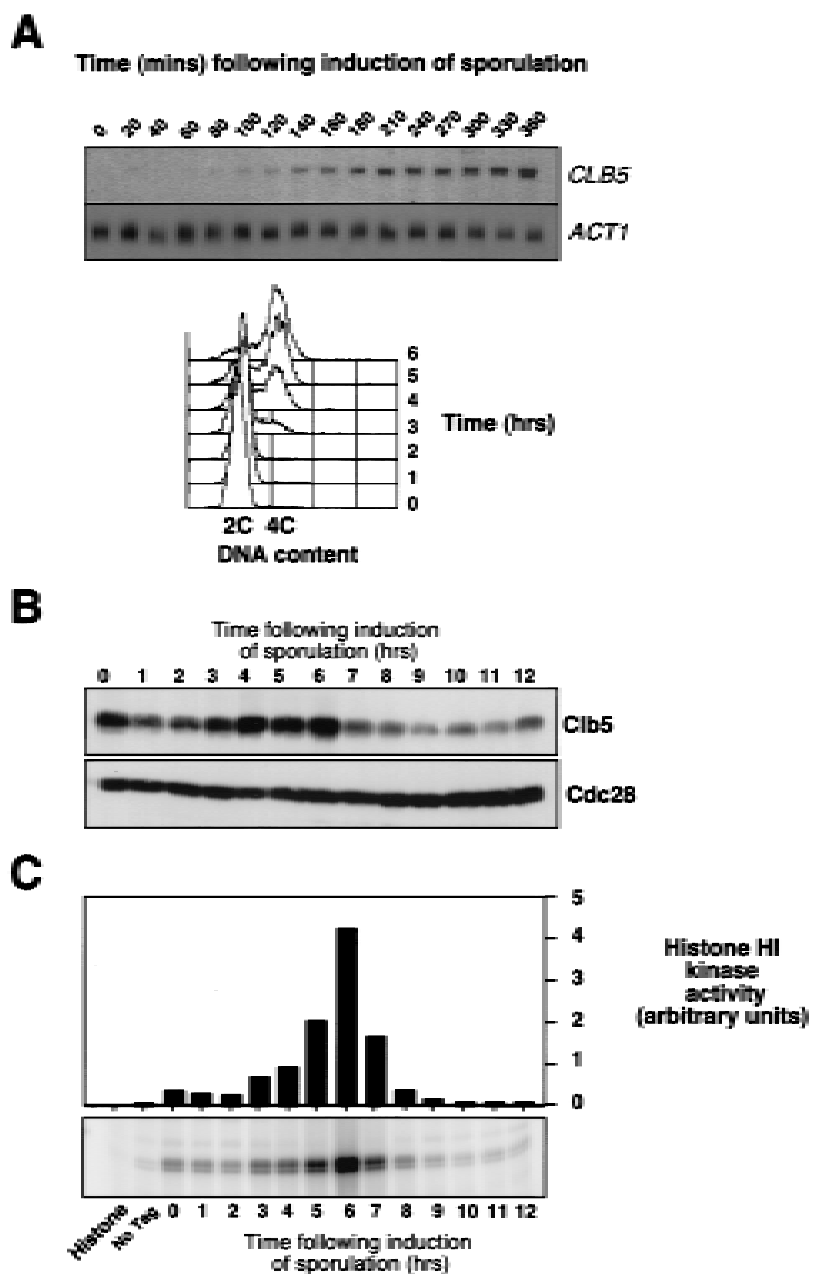

Figure 2. CLB5 RN A, protein, and associated kinase accumulate prior to and throughout meiotic $S$ phase. (A) Synchronous population of $G_{1}$ cells, isolated by centrifugal elutriation was induced to sporulate and samples collected at the indicated times were analyzed by $\mathrm{N}$ orthern blotting for the abundance of CLB5 and ACT1 transcripts (top), or for DN A content by FACS (bottom). (B) Western blot analysis of Clb5 protein abundance in a culture grown to late log phase and then induced to sporulate at time 0 . The Western blot was probed with $12 \mathrm{CA} 5$ anti $\mathrm{HA}$ antibody to detect $\mathrm{Clb5HA}$ and with anti-Cdc28 antibody as a control for loading. (C) Kinase activity associated with Clb5 was analyzed by immunoprecipitation with anti-HA antibody from samples of CLB5HA/CLB5HA diploids that had been induced to sporulate. Immune complexes were extensively washed and then assayed for kinase activity with histone $\mathrm{H} 1$ as a substrate.

temperature because of the inherent temperature sensitivity of meiosis. Therefore, to determine whether premei otic $S$ phase requi red a $\mathrm{Cl}$ b-dependent CDK function, we asked whether cells could sporul ate in the absence of Clb-associated CDK activity. This was accomplished by expressing a hyperstabilized form of the Clb-specific CDK inhibitor Sicl (SIC1 $\Delta \mathrm{P}$ ) (Verma et al. 1997) in sporulating cells under the control of the meiosis-specific IME2 promoter. Whereas wild-type cells efficiently replicated DNA following the induction of sporulation, 
A

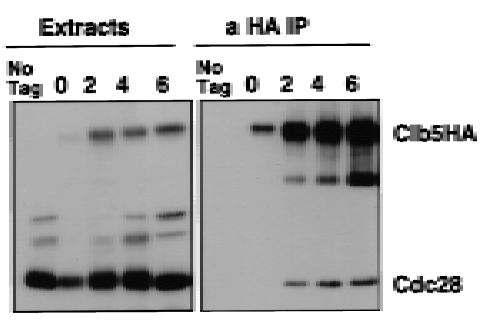

B
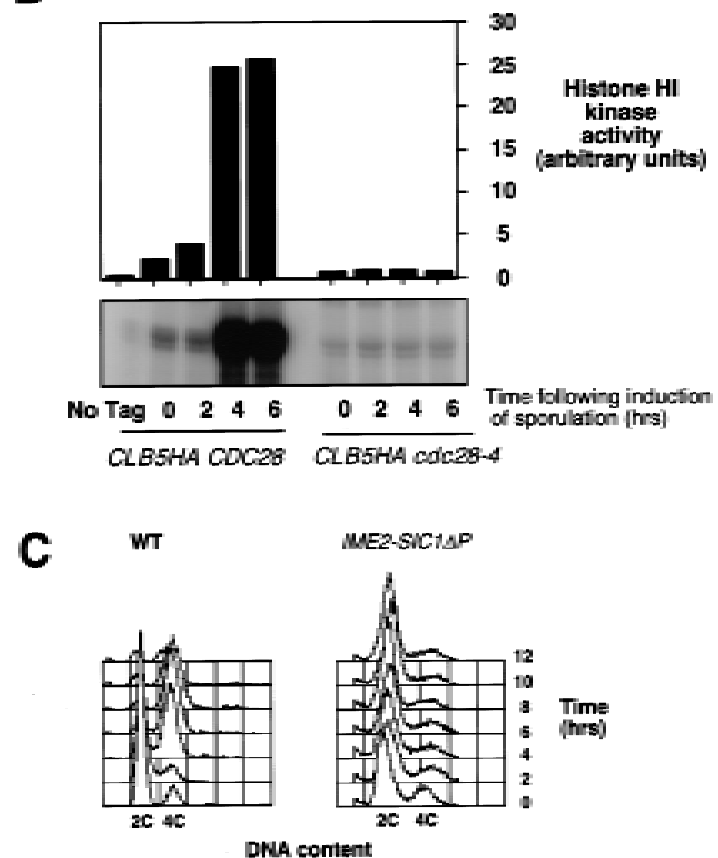

Figure 3. Histone $\mathrm{HI}$ kinase activity associated with $\mathrm{Clb5}$ during sporulation is $\mathrm{Cdc} 28$ dependent. (A) Whole cell extract (50 $\mu \mathrm{g}$ ) or anti-HA immunoprecipitates (from $1 \mathrm{mg}$ of total protein) from either wild-type diploid cells (No Tag) or CLB5HA/ CLB5HA diploids were separated by gel electrophoresis and probed for $\mathrm{Clb5HA}$ and $\mathrm{Cdc} 28$. (B) Histone $\mathrm{H} 1$ kinase activity associated with $\mathrm{Clb5HA}$ immune complexes prepared from diploid strains expressing wild-type Cdc28 (CLB5HA CDC28), a temperature-sensitive Cdc28-4 (CLB5HA cdc28-4), or a wildtype $\mathrm{Cdc} 28$ with untagged CLB5 (N o Tag). Strains were grown and induced to sporulate at the permissive temperature of $28^{\circ} \mathrm{C}$ and kinase activity was assayed at $25^{\circ} \mathrm{C}$. (C) DN A content over a time course of sporulation of wild-type diploids and diploids that express a stabilized version of the $\mathrm{Clb} / \mathrm{Cdc} 28 \mathrm{CDK}$ inhibitor $\mathrm{SIC} 1(\mathrm{SIC} 1 \Delta \mathrm{P})$ under the regulation of the meiosis specific IME2 promoter.

diploid cells homozygous for the IME2-SIC1 $1 \Delta \mathrm{P}$ construct were unable to progress into premeiotic $S$ phase and arrested with $a G_{1}$ DNA content (Fig. 3C). This was consistent with the effect of inactivating cyclin-CDK activity with stabilized Sicl in mitotic cells. The most direct interpretation of this series of experiments is that Clb-associated Cdc28 CDK activity is essential for premeiotic S phase, suggesting that the results of experiments with temperature-sensitive cdc28 mutants have been misinterpreted. However, the formal possibility remains that $\mathrm{Clb5}$ activates another Sicl-sensitive CDK that is essential for this process.

clb5 clb6 mutants proceed through the meiotic program in the absence of replicated DNA and undergo a catastrophic $M$ phase

Chemical inhibitors or mutations that block premei otic DN A replication al so block progression into the mei otic program, decrease or prevent meiotic recombination, and inhibit the expression of middle and late sporulation genes (Simchen et al. 1976; Schild and Byers 1978; Mitchell 1994). Thus, the failure to replicate chromosomal DNA would al one be sufficient to explain the inability of $\mathrm{clb5} / \mathrm{clb} 5 \mathrm{clb} 6 / \mathrm{clb} 6$ mutants to complete meiosis and undergo sporulation, as indicated by the sporulation defect observed in $\mathrm{HU}$-treated cel Is (Table 1). However, cells treated with an arresting concentration of HU (100 mm) remain viable and are competent to return to mitotic growth when plated onto rich medium lacking $\mathrm{HU}$ (Fig. 4B). In contrast, both $\mathrm{clb5} / \mathrm{clb5}$ and $\mathrm{clb5} /$ clb5 clb6/clb6 mutants rapidly lose the ability to form colonies on rich growth medium when they are removed from sporulation conditions (Fig. 4A). This suggested that these mutants had an additional defect that caused them to lose viability during sporulation or that simply prevented them from returning to mitotic growth.

We hypothesized that the mutant cells had become committed to meiotic progression despite having completed little or no DN A replication. The clb5/clb5 (not shown) and $\mathrm{clb5} / \mathrm{clb} 5 \mathrm{clb} 6 / \mathrm{clb} 6$ mutant diploids progressed into the meiotic program based on four distinct criteria. First, the mutants executed the normal program of meiotic gene expression as indicated by the transcription of both early (IME1 and IME2) and middle sporula-
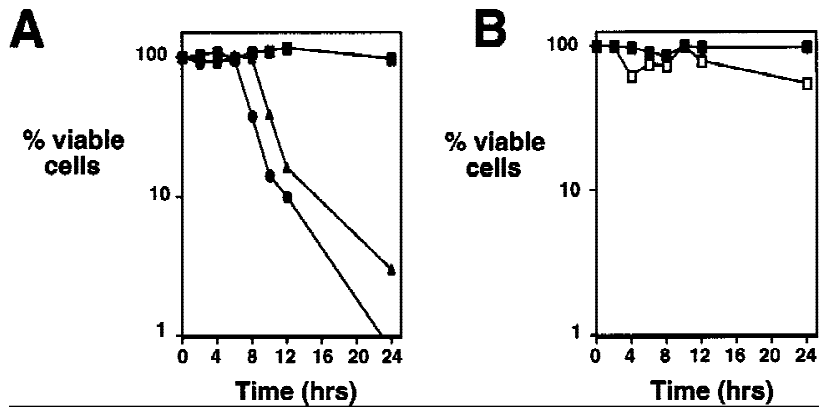

Figure 4. $\mathrm{clb} 5$ and $\mathrm{clb} 5 \mathrm{clb} 6$ mutant diploids rapidly lose viability when induced to sporulate. (A) Synchronous population

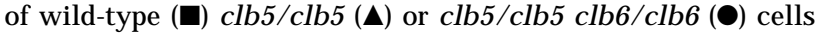
were isolated by centrifugal elutriation and induced to sporulate. The viability of cells during the timecourse was determined by their ability to return to mitotic growth when plated onto rich growth medium at the times indicated. Values represent the average number of colonies derived from two independent samples. (B) Viability of wild-type diploid cells induced to sporulate in the absence of $\mathrm{HU}(\boldsymbol{\square})$ or in the presence of $100 \mathrm{~mm}$ HU ( $\square$ ). All of the values represent the average number of colonies from two independent samples. 
A

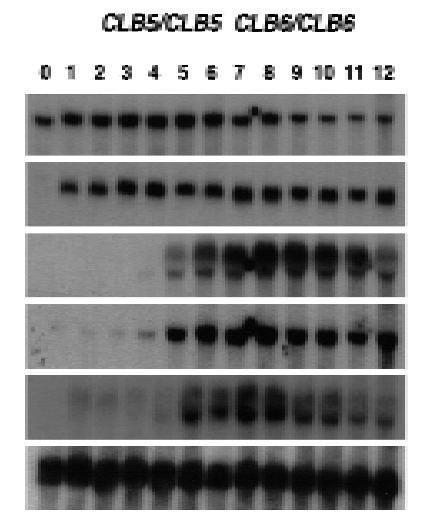

B

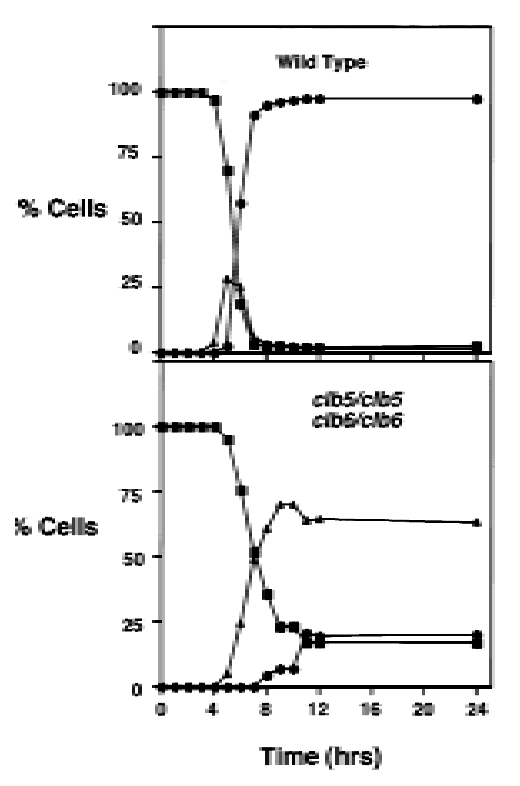

clbsibs cibercibs

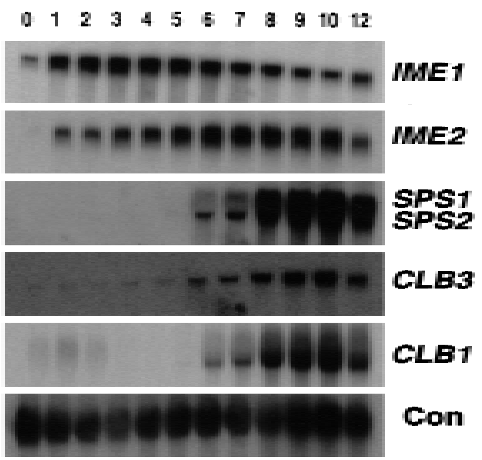

C

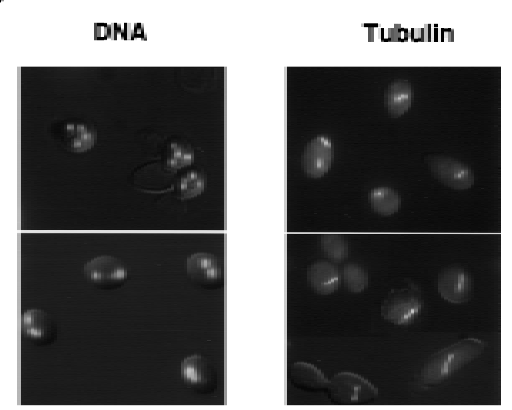

E

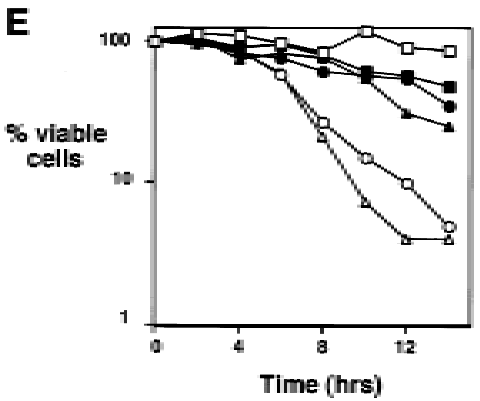

Figure 5. $\mathrm{clb} 5 / \mathrm{clb} 5 \mathrm{clb} 6 / \mathrm{clb} 6$ mutants attempt to progress through meiotic development despite being unable to replicate DNA. (A) Northern blots made with RNA samples from sporulating wild-type diploids (left) or $\mathrm{clb5} / \mathrm{clb5} \mathrm{clb6} / \mathrm{clb} 6$ mutants (right) were sequentially hybridized with probes recognizing RNA transcripts from the early (IMEI and IME2) and middle (SPS1 and SPS2) sporulation genes and the B-type cyclins, CLB1 and CLB3. The constitutively expressed gene $C 4 / 2$ was used as a loading control (Su and Mitchell 1993). (B) Chromatin segregation in wild-type diploids (top) or $\mathrm{clb} 5 / \mathrm{clb} 5 \mathrm{clb} 6 / \mathrm{clb} 6$ mutants (bottom) following induction of sporulation. The proportion of cells having either one ( $\mathbf{\square})$, two $(\boldsymbol{\Lambda})$, or more than two $(\bullet)$ masses of divided chromatin was determined by fluorescence microscopic examination of DAPI-stained cells following induction of sporulation in synchronized populations. (C) Chromatin masses in a representative group of cells from the 8-hr time point of B. Chromatin was visualized by propidium iodide fluorescence and is overlaid on a DIC image of the same cells. The wild-type cells (top) have undergone $\mathrm{MI}$ and $\mathrm{MII}$, whereas most of the $\mathrm{clb} 5 / \mathrm{clb} 5 \mathrm{clb} 6 / \mathrm{cl} b 6$ mutants (bottom) have apparently undergone a single meiotic division. (D) Meiotic spindles visualized by GFP-tubulin fluorescence in wild-type (top) and $\mathrm{clb} 5 / \mathrm{clb} 5 \mathrm{clb} 6 / \mathrm{clb} 6$ (bottom) $6 \mathrm{hr}$ following the induc-tion of sporulation. The fluorescence image is overlaid on a DIC image of the same cells. (E) Lethal meiosis of clb5/clb5 clb6/clb6 mutants is partially rescued by inhibiting spindle formation. Viability in synchronized populations of wild-type $(\square, \mathbf{\square}), \mathrm{clb5} /$ clb5 $(O, \bullet)$ or $\mathrm{clb5} / \mathrm{clb5} \mathrm{clb6} / \mathrm{clb} 6(\triangle, \mathbf{\Lambda}) \mathrm{mu}-$ tant cells treated (solid symbols) with nocodazole $(20 \mu / \mathrm{ml}) /$ benomyl $(30 \mu \mathrm{g} / \mathrm{ml})$ or left untreated (open symbols) following induction of sporulation. The percent of viable cells was determined by their ability to return to mitotic growth when removed from sporulation conditions and plated onto rich growth medium lacking any inhibitors. Values represent the average number of col onies derived from two independent samples.

tion genes (SPS1, SPS2) (Fig. 5A). Two B-type cyclins, CLB1 and CLB3, were coordinately expressed with SPS1 and SPS2 in both wild-type and mutant cells (Fig. 5A). Surprisingly, despite their continued expression, these cyclins were insufficient to complement the $S$ phase defect of either the $\mathrm{clb5} / \mathrm{clb} 5$ or $\mathrm{clb5} / \mathrm{clb} 5 \mathrm{clb} 6 / \mathrm{clb} 6 \mathrm{mu}$ tant as has been observed in the mitotic cell cycle. N ext, fluorescence microscopy reveal ed the appearance of two discrete DNA masses in a substantial proportion of the $\mathrm{clb5} / \mathrm{clb5}$ (not shown) and clb5/clb5 clb6/clb6 mutants (Fig. 5B,C) coincident with execution of the first meiotic $M$ phase in wild-type controls. This was followed by the appearance of three or more chromatin masses in a small proportion of the cells consistent with execution of meiosis II. Finally, the appearance of two or more DNA masses was correlated with the elongation of $M$ phase spindles visualized by green fluorescent protein (GFP)tubulin fluorescence (Fig. 5D) and with the appearance of separated spindle pole bodies (SPBs) as visualized independently by use of a GFP-tagged SPB component $\mathrm{N}$ uf2 (data not shown). The observations indicate that the $\mathrm{clb5} / \mathrm{clb5} \mathrm{clb} 6 / \mathrm{clb} 6$ mutants attempted to proceed through meiotic chromosome divisions despite the inability to replicate DNA.

The loss of viability in clb5/clb5 clb6/clb6 mutants correlated well with the time at which wild-type cells initiated the segregation of chromosomal DNA at meiosis I (see Fig. 5B, top). Consistent with the view that progression into meiotic $M$ phase in the absence of fully replicated DNA is the cause of lethal ity in $\mathrm{clb} 5 / \mathrm{clb} 5$ and $\mathrm{clb5} / \mathrm{clb} 5 \mathrm{clb} 6 / \mathrm{clb} 6$ mutants, the inviability (but not the sporulation defect) of both strains was partially suppressed by treatment with chemical inhibitors of $M$ phase spindle assembly (nocodazole and benomyl) subsequent to the induction of meiosis (Fig. 5E). We assume that the failure of this treatment to more fully suppress 
the inviability of the mutant cells was caused by the toxicity of the inhibitors because the same treatment reduced the viability of wild-type cells. In fact, it appears that the rescue was very efficient because the proportion of viable cells in the inhibitor-treated wild-type and mutant populations is quite similar. Thus, the inviability of the strains deficient in CLB5 or CLB5 and CLB6 results from their inability to restrict meiotic $M$ phase in the absence of fully replicated chromosomes.

\section{A MEC 1-dependent DNA replication checkpoint operates during mei osis}

The loss of viability observed in clb5/clb5 clb6/clb6 mutants undergoing meiosis is consistent with the inability of those mutants to activate a checkpoint coupling completion of DNA replication to $M$ phase. Checkpoint controls that monitor DNA damage or imperfect DNA synthesis, recombination, spindle formation, and chromosome segregation have been identified in cells undergoing meiosis (Weber and Byers 1992; Rose and Holm 1993; Thorne 1993; Li and N icklas 1995; Lydall et al. 1996; Xu et al. 1997). However, it was possible that wild-type cells undergoing meiosis lacked a functional DNA replication checkpoint. Such a checkpoint operating during meiotic development would be expected to prevent the initiation of chromosome divisions when DNA replication is blocked by an arresting dose of the DN A synthesis inhibitor $\mathrm{HU}$ and to del ay divisions if the completion of DN A replication is slowed by a subarresting dose of $\mathrm{HU}$. To establish the existence of such a checkpoint, cells were induced to sporulate and then treated with $100 \mathrm{~mm} \mathrm{HU}$, a concentration sufficient to block DNA replication. HU treatment prevented both sporulation (Table 1 ) and execution of $M$ phase as indicated by the lack of chromatin segregation (Fig. 6A, bottom). Unlike clb5/clb5 clb6/clb6 mutants, HU-treated wild-type cells maintained high viability on return to growth (Fig. 6A, top). Their ability to maintain viability during this treatment depended on the activity of the MEC 1 gene, which is required for both the mitotic DN A replication and DN A damage checkpoints (Weinert et al. 1994; Lydall et al. 1996). As a result, mecl-1/mecl-1 mutants proceeded through meiotic $M$ phase in the presence of $\mathrm{HU}$ with the same kinetics as untreated wildtype cells (data not shown) and rapidly lost viability (Fig. $6 \mathrm{~A}$, top).

A similar experiment was performed by use of an $\mathrm{HU}$ concentration that was sufficient to delay, but not to block, progress through DNA replication (Tsui et al. 1997). Wild-type cel Is treated with $2.5 \mathrm{~mm}$ HU proceeded slowly through $\mathrm{S}$ phase, but ultimately completed meio-
A
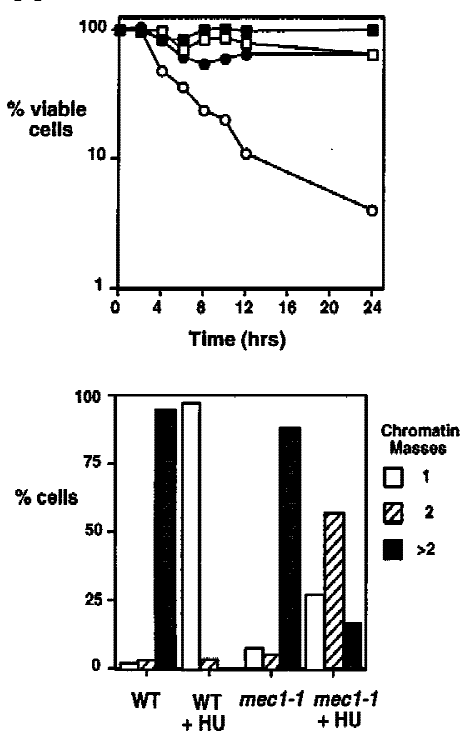

B
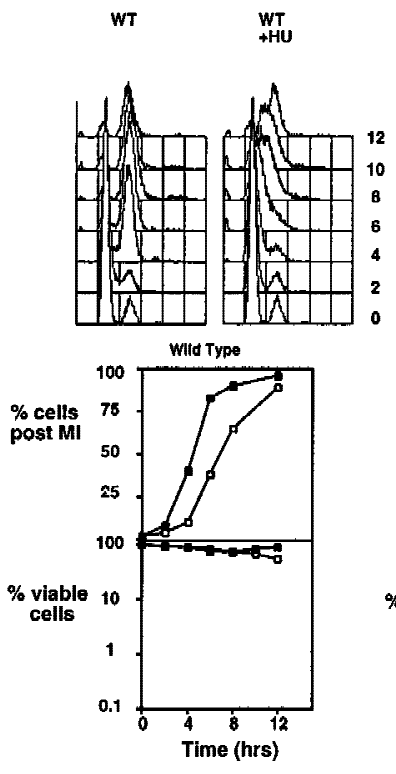

C meot-1 $\underset{\substack{\text { mect-1 } \\+\mathrm{HL}}}{\cos }$
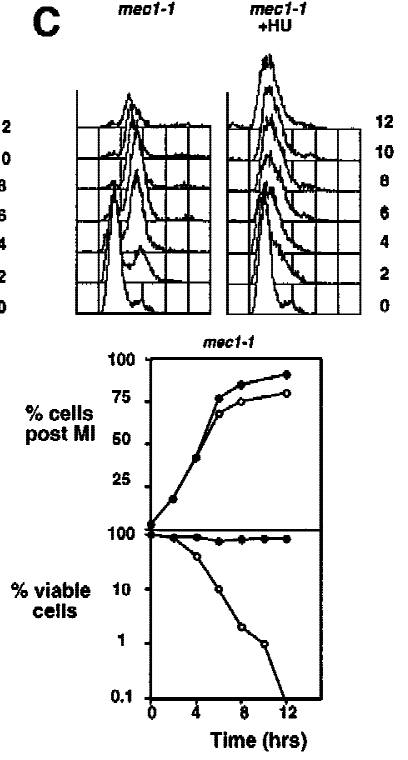

\section{D}

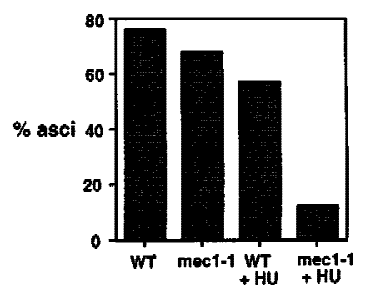

Figure 6. A DNA replication checkpoint dependent on MEC1 operates during meiotic development. (A) (Top) Viability of wild-type diploid cells $(\square, \mathbf{\square})$ or mecl-1/mecl-1 mutants $(O, \bullet)$ that were either untreated (solid symbols) or treated with 100 mM HU (open symbols) following induction of sporulation. Viability was assessed by removing samples of each culture at the indicated time and plating onto rich growth medium lacking HU. (Bottom) Percent of wild-type or mec1-1/mecl-1 cells that display one, two, or more than two separated chromatin masses following $12 \mathrm{hr}$ of sporulation in the presence or absence of $100 \mathrm{~mm} H \mathrm{HU}$. (B) (Top) DN A content of wild-type diploids induced to sporulate in the presence of $2.5 \mathrm{~mm} \mathrm{HU}$, a subarresting concentration, at the indicated times following induction of sporulation determined by FACS analysis. (Bottom) Segregation of chromatin, determined by DAPI staining and cell viability as measured by ability to return to growth in wild-type diploids during sporulation in the absence ( $\square$ ) or in the presence ( $\square$ ) of $2.5 \mathrm{~mm} \mathrm{HU}$. (C) (Top) DN A content of mec1-1/mecl-1 diploids induced to sporulate in the presence of $2.5 \mathrm{~mm} \mathrm{HU}$, a subarresting concentration as determined by FACS analysis. (Bottom) Segregation of chromatin and cell viability of mec1-1/mecl-1 diploid cells during sporulation in the absence $(-)$ or presence $(O)$ of $2.5 \mathrm{~mm} \mathrm{HU}$. (D) Percent of wild-type or mec1-1/mec1-1 diploid cells forming asci after being sporulated for $24 \mathrm{hr}$ in the presence or absence of $2.5 \mathrm{~mm} \mathrm{HU}$. 
sis and sporulated, al beit with somewhat reduced efficiency (Fig. 6B,D). Importantly, chromatin segregation in HU-treated wild-type cells was substantially delayed relative to untreated cells (Fig. 6B, bottom). The HUinduced $\mathrm{M}$-phase delay was abolished in the mec1-1/ mec1-1 mutants (Fig. 6C, bottom). Consistent with their failure to delay $M$ phase in the presence of $\mathrm{HU}$, the mec1-1/mecl-1 mutant cells suffered a drastic reduction in viability (Fig. 6C, bottom) and efficiency of sporulati on relative to either untreated cells or $\mathrm{HU}$-treated wildtype cel Is (Fig. 6D). These data provide strong support for the existence of a checkpoint restricting meiotic $M$ phase in the absence of fully replicated DNA.

The meiotic DNA replication checkpoint is inoperable in clb5 clb6 mutants

The failure of $\mathrm{clb5} / \mathrm{clb5} \mathrm{clb6} / \mathrm{clb} 6$ mutant diploids to restrict meiotic $M$ phase in the absence of DNA replication suggests that such cells lack the ability to activate the DNA replication checkpoint. This predicts that treatment of the mutant cells with $\mathrm{HU}$ will neither rescue them from inviability, nor restrict the segregation of chromosomal DNA in the absence of DNA replication. Low doses of $\mathrm{HU}$, sufficient to delay $\mathrm{MI}$ in wild-type cells (Fig. 7A, top), failed to delay the appearance of divided chromosome masses in $\mathrm{clb5} / \mathrm{clb5} \mathrm{clb} 6 / \mathrm{clb} 6 \mathrm{mu}-$ tants (Fig. 7B, top), or to rescue the mutants from the profound loss of viability observed on return to growth (Fig. 7B, bottom). A high dose of $\mathrm{HU}$ provided only a small degree of rescue to the $\mathrm{clb} 5 / \mathrm{clb} 5 \mathrm{clb} 6 / \mathrm{clb} 6 \mathrm{mu}-$ tants and was largely unable to prevent the onset of meiosis I (Fig. 7B, top). The degree of viability loss in $\mathrm{clb5} / \mathrm{clb5} \mathrm{clb} 6 / \mathrm{clb} 6$ mutants is similar to that of mec1/ mecl mutants, suggesting that the small degree of rescue provided by the high dose of $\mathrm{HU}$ is independent of the MEC1-mediated checkpoint. The inability of HU to delay or prevent mei otic chromosome segregation demonstrates that the DNA replication checkpoint is inac- tive and is not able to be activated in clb5/clb5 clb6/ clb6 mutants.

In contrast, clb5/clb5 clb6/clb6 mutants are compe tent to respond to DN A damage induced during sporulation by delaying meiotic $M$ phase. Treatment with $\gamma$ irradiation provoked a response that was able to delay the onset of the first meiotic division by $\sim 2 \mathrm{hr}$ in both wild-type and clb5/cl b5 clb6/clb6 mutant cells (Fig. 7C). Similarly, when wild-type or clb5/clb5 clb6/clb6 mutants are treated with UV irradiation, chromosome segregation is del ayed (data not shown). These data demonstrate that, despite their defect in the activation of a DNA replication checkpoint, clb5/clb5 clb6/clb6 mutants retain the ability to respond to DNA damage by delaying progression into $M$ phase.

\section{Discussion}

CLB5 and CLB6 regulate premei otic S phase

Clb5 and Clb6 are essential for sporulation because they are required for premeiotic DNA replication. It is surprising that these cyclins are absolutely required during meiotic development because their loss merely delays the initiation and progression through $S$ phase during the mitotic cell cycle (Epstein and Cross 1992; Kuhne and Linder 1993; Schwob and N asmyth 1993). The ability of CLB1-CLB4 to assume the S-phase function normally performed by CLB5 and CLB6, may explain why these two cyclins are dispensable during mitotic growth, because cells deficient in all six CLBs arrest at the $\mathrm{G}_{1} / \mathrm{S}$ phase boundary (Schwob et al. 1994). Furthermore, the defect resulting from inactivation of all six CLBs can be suppressed by ectopic expression of CLB1 (S. Haase and $\mathrm{S}$. Reed, pers. comm.). In cells undergoing meiosis, CLB1, CLB3, and CLB4 are expressed even when CLB5 and CLB6 are inactivated. Yet, these B-type cyclins fail to perform the essential CLB-dependent $S$ phase function. That other B-type cyclins are functional and become active in $\mathrm{clb5} / \mathrm{clb5} \mathrm{clb} 6 / \mathrm{clb} 6$ mutants is demon-
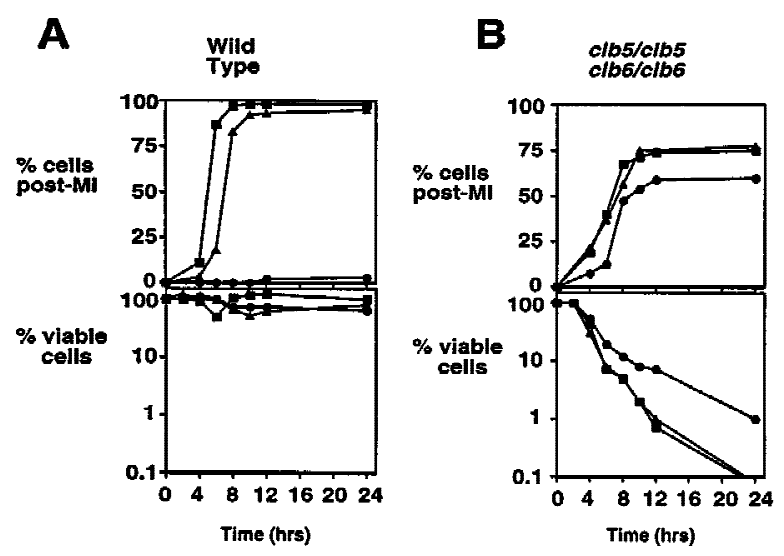

Figure 7. $\mathrm{clb} 5 / \mathrm{clb} 5 \mathrm{clb} 6 / \mathrm{clb} 6$ mutants are unable to delay chromosome segregation in response to $\mathrm{HU}$, but can delay in response to DN A damage. Wild-type (A) or clb5/clb5 clb6/clb6 (B) diploids were induced to sporulate in the absence of $\mathrm{HU}(\boldsymbol{\square})$, or with

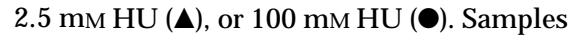
obtained at the indicated intervals were stained with DAPI to determine when chromosome segregation occurred (top, A,B), or were diluted and plated to determine viability (bottom, A,B). (C) Wild-type $(\square, \boldsymbol{\square})$ or $\mathrm{clb5} / \mathrm{clb5} \mathrm{clb} 6 / \mathrm{clb} 6(\bigcirc, \bullet)$ diploids were induced to sporulate at $30^{\circ} \mathrm{C}$ and after $2 \mathrm{hr}$ were subjected to either mock irradiation (open symbols) or $\gamma$ irradiation with 200 gy (solid symbols). Following treatment, cultures were returned to $30^{\circ} \mathrm{C}$ and samples withdrawn at the indicated times and stained with DAPI to monitor chromosome segregation. 
strated both by their pattern of expression and their ability to promote Clb-dependent events associated with meiotic $M$ phase. These include separation of SPBs and elongation of meiotic spindles (Fitch et al. 1992; Dahmann and Futcher 1995). Ironically, it is likely the capacity of those B-type cyclins to promote meiotic $M$ phases that results in lethality in Clb5 Clb6-deficient cells. Consistent with that idea, inhibition of all Clbassociated CDK activity by overexpression of Sicl prevents both DNA replication and chromosome segregation, whereas inactivation of CLB5 and CLB6 prevents DN A replication but not chromosome segregation.

Several lines of evidence suggest that CIb5 and Clb6 perform their essential premeiotic $S$ phase function by activating the Cdc28 CDK. We have shown that CIb5 associates with Cdc28 to form an active protein kinase during meiosis. In addition, expression of Sicl, an inhibitor of the Clb-associated forms of the Cdc28 CDK, is sufficient to block premeiotic $S$ phase as well as subsequent meiotic $M$ phases. This is consistent with the observation that during the mitotic cell cycle inhibition of $\mathrm{Clb} / \mathrm{Cdc} 28 \mathrm{kinase}$, either by the del etion of CLB1-CLB6 or by overexpression of Sicl, prevents DNA replication (Schwob et al. 1994; Verma et al. 1997). The fact that premeiotic S phase is dependent on $\mathrm{Cdc} 2$ in $\mathrm{S}$. pombe further supports this contention. However, in agreement with the observations of Shuster and Byers (1989), we have been unable to abrogate mei otic DN A synthesis by use of temperature-sensitive cdc28 mutants. Although this may simply reflect our inability to effectively inactivate $\mathrm{Cdc} 28$ under conditions that are permi ssive for the inherentl y temperature-sensitive mei otic devel opmental pathway, we cannot formally exclude the possibility that Clb5 and Clb6 perform a Cdc28-independent function that is required for mei otic $D N A$ replication.

The failure of CLB1, CLB3, and CLB4 to complement a deficiency of CLB5 and CLB6 could be explained if a window of opportunity exists in which Clb-dependent kinase activity can activate DNA replication. Because the expression of CLB5 and CLB6 is rapidly followed by the induction of CLB1-CLB4 during mitotic growth, these four mitotic cyclins can accumulate during the permissive window of time and promote initiation of $\mathrm{S}$ phase. However, during meiosis, the interval between the initiation of $S$ phase and CLBI accumulation is greatly prolonged. As a consequence, CLB1, CLB3, and CLB4 might accumulate too late to adequately replace the S phase function of CLB5 and CLB6 (i.e., subsequent to the window of opportunity) and would simply promote meiotic $M$ phase. A number of scenarios that might lead to the existence of such a window can be envisioned. One reasonable hypothesis is that some aspect of the prereplication complex (pre-RC) is inherently unstable and requires $\mathrm{Cl}$ lb-associated kinases to act prior to decay of the labile state. This hypothesis is not unlike the point of no return hypothesis proposed to explain the requirement for $\mathrm{Cdc} 6$ in activating origins of replication (Piatti et al. 1996). That hypothesis holds that if Cdc6 is not provided prior to the activation of Clb-associated kinase activity, it is not able to promote replication, whereas we propose that if $\mathrm{Cl}$-associated kinase is not provided within a specific time frame subsequent to licensing of origins during meiosis, DNA replication will not ensue. N everthel ess, that activity will promote meiotic $M$ phases. Although it is a formal possibility that CLB5 and CLB6 serve some unique function in the activation of premeiotic DNA replication that can not be performed by other forms of Clb-CDK, we think this unlikely because other Clbs can activate DNA replication very effectively during mitotic growth. However, it is also possible that chromosomes become refractory to DNA replication as a consequence of meiotic progression.

The meiotic DNA replication checkpoint is inoperable in clb5 clb6 mutants

The rapid loss of viability that occurs when clb5/clb5 clb6/clb6 mutants enter the meiotic pathway was unexpected because it has been shown that cells can return to mitotic growth if arrested at virtually any stage of meiotic development (Honigberg and Esposito 1994). However, the ultimate demise of the clb5 cl b6 mutants stems not from their inability to replicate DN A, but from their inability to restrain chromosome segregation in the absence of DN A replication. This phenotype suggests that the machinery responsible for detecting or responding to a failure in DNA synthesis is defective in these mutants. This defect appears to be meiosis specific because clb5 clb6 mutants display no checkpoint defects during mitotic growth ( $\mathrm{Li}$ and Cai 1997). Our analysi s revealed that a single attempt at chromosome segregation occurs in a relatively large proportion of the $\mathrm{clb5/clb5} \mathrm{clb} 6 / \mathrm{clb} 6$ mutants. If chromosomes do not undergo pairing in the absence of replication, the outcome of this attempted division would likely result in unequal chromosome segregation and perhaps in chromosome breakage. DNA damage resulting from that division would likely prevent meiotic progression via the DNA damage checkpoint. This scenario is consistent with our observation that only a small number of the mutant cells ever develop four independent DNA masses.

Although the unreplicated homologous chromosomes may undergo some form of meiotic pairing (Weiner and Kleckner 1994), it is not clear whether such paired chromosomes would behave like those participating in a conventional synapsis (Kleckner 1996; Roeder 1997). One approach to establishing whether chromosomes undergo productive synapsis is to establish the extent to which they recombine. On the basis of an analysis of the rate of recombination of heteroalleles observed on returning cells to growth in rich medium, we conclude that the level of recombination is modestly reduced and delayed in clb5/clb5 mutants relative to wild-type cells. In contrast, clb5/clb5 clb6/clb6 mutants appear not to undergo significant levels of recombination during meiosis (data not shown). Although it might be concluded that the capacity of the later strain to undergo recombination is severely affected, simple interpretations of these results are compromised by the exceedingly small number 
of viable cells recovered following return to growth as time following induction of meiosis increases (Fig. 4).

Stable arrest in response to inhibitors and mutations that block DNA replication during meiosis is well documented (Simchen et al. 1976; Schild and Byers 1978). This response can now be attributed to the existence of a MEC 1-dependent checkpoint that monitors DNA replication and blocks meiotic progression. The same checkpoint is required to delay chromosome segregation when the completion of DNA synthesis is delayed. The target of the DNA replication checkpoint in the mitotic cell cycle is unclear. However, it is known that when replication is blocked with $\mathrm{HU}$ during the mitotic cell cycle expression of CLB1-CLB4 persists and a high level of histone $\mathrm{H} 1$ kinase activity accumulates (Stueland et al. 1993). When cells undergoing meiosis are similarly treated, they fail to express middle sporulation genes, including CLB1 (Mitchell 1994; data not shown). Although the status of Clb-associated CDK activity in those cells is unclear, they are able to stably arrest without segregating chromosomes and remain viable. It has recently been shown that a similar effect on CLB1 expression occurs in response to DNA damage caused by failure to complete recombination, which then results in a pachytene arrest (Chu and Herskowitz 1998). This restraint mechanism invoked by the DNA replication checkpoint machinery is clearly circumvented in clb5/ clb5 clb6/clb6 mutants, which express CLB1 and undergo chromosome segregation.

It is not clear why CLB5 and CLB6 are specifically required for activation of the DNA replication checkpoint. They may be required either to generate a signal concerning the status of DNA replication or to respond to such a signal. The mutants are not generally defective in the generation of checkpoint signal s that prevent meiotic $M$ phase because the DNA damage checkpoint is operable in those cells. Several studies suggest that induction of the DNA replication checkpoint during mitotic growth depends on the correct assembly and activation of origins of replication (Li and Deshaies 1993; Piatti et al. 1995; Toyn et al. 1995; Tavormina et al. 1997). In cells arrested by inhibitors of DN A replication, such as HU, at least some pre-RCs are converted to RCs (Diffley et al. 1994) leading to the hypothesis that either the stalled replication forks or some aspect of the activated origin may act as the signal. This is consistent with the observation that mutations which prevent origin activation fail to activate the DNA replication checkpoint (Piatti et al. 1995; Toyn et al. 1995; Tavormina et al. 1997) presumably because no replication signal can be generated. A similar defect may explain the behavior of $\mathrm{cl}$ b5/ clb5 cl b6/ cl b6 mutants during mei osis. Like Cdc6, Clb5 has been shown to interact with origin components, and has been implicated in the activation of replication origins (Epstein and Cross 1992; Kuhne and Linder 1993; Schwob and N asmyth 1993; El sasser et al. 1996; Zou and Stillman 1998). That the meiotic DN A replication checkpoint depends on origin activation may not be inconsistent with the ability of clb5/clb5 mutants to undergo some DNA replication, because $M$ phase and concomitant loss of viability precedes detectable DNA replication in those cells. Nevertheless, at least some of those cells appear to progress through meiotic $M$ phase in the presence of replicating DNA, suggesting that $\mathrm{Cl}$ b5 may also be involved in generating a DNA replication signal. Clb5 need not be the signaling molecule in either of these cases. Instead, Clb5 may be required for correct organization or activation of the replication complex and it may be the state of that complex that is monitored by the checkpoint machinery.

\section{Materials and methods}

Strains and growth conditions

All yeast strains used in this study were derived from either BF264-15Du (MATa adel bar1 $\Delta$ his2 leu2 trp1-1 ura3 $\Delta$ ) (Richardson et al. 1989) or SK1 (Kane and Roth 1974) MATa/ $\alpha$ ho::LYS2/ho::LYS2 lys2/lys2 ura3/ura3 arg4Bgl/arg4Nsp leu2::hisG/leu2::hisG trp1::hisG/trpl::hisG his4-X/his4-B (Lydall et al. 1996). The relevant genotypes of strains used in this study are shown in Table 2. The phenotypes of $\mathrm{clb5}, \mathrm{clb} 6$, and clb5 clb6 mutant diploids was comparable in both the BF26415Du and SK 1 strain backgrounds despite the inherent differences in sporulation efficiency of the wild-type parents. Only

Table 2. S. cerevisiae strains used in this study

\begin{tabular}{|c|c|c|}
\hline Strain & Rel evant genotype & Source \\
\hline DSY 1089 & $\mathrm{MATa} / \alpha$ & Lydall et al. (1996) \\
\hline DSY 960 & MATa/ $\alpha$ clb5::U RA3/" & this study \\
\hline DSY 945 & MATa/ $\alpha$ clb6::TRP1/" & this study \\
\hline DSY 984 & MATa/ $\alpha$ clb5::URA3/" clb6::TRP1/" & this study \\
\hline DSY 1092 & MATa/ $\alpha$ clb5::KAN ${ }^{R} / "$ clb6::TRP1/" & this study \\
\hline DSY 1029 & MATa/ $\alpha$ CLB5/clb5::URA3 CLB6/clb6::TRP1 & this study \\
\hline DSY 1106 & MATa/ $\alpha$ URA3::IME2-SIC1 $\Delta \mathrm{P} /{ }^{\prime \prime}$ & this study \\
\hline DSY 1061 & MATa/ $\alpha$ TU B1-GFP [LEU 2] & this study \\
\hline DSY 1062 & MATa/ $\alpha$ clb5::KAN/" clb6::TRP1/" TU B1-GFP [LEU 2] & this study \\
\hline DSY 1001 & MATa/ $\alpha$ nuf2::NU F2-GFP::KAN ${ }^{R} / "$ & this study \\
\hline DSY 1002 & MATa/ a clb5::URA3/" clb6::TRP1/" nuf2::NUF2-GFP::KANR/" & this study \\
\hline DSY 1057 & $\mathrm{MATa} / \alpha \mathrm{mecl}-1 / \mathrm{mecl}-1$ & Lydall et al. (1996) \\
\hline DSY 1000 & $\mathrm{MATa} / \alpha$ CLB5HA-TRP1/" & this study \\
\hline DSY 1079 & MATa/ $\alpha$ cdc28-4/" CLB5HA-TRP1/" & this study \\
\hline
\end{tabular}


data obtained from SK1 strains is presented in this report. All strains were constructed by standard genetic methods (Rose et al. 1990). CLB5 was inactivated by replacing a 1.5-kb Aflll fragment that contains the entire ORF with either a 1.1-kb URA3 fragment or a kanamycin resistance gene $\left(K A N^{R}\right)$ from pFA6KanM X2 (Wach et al. 1994). CLB6 was inactivated by replacing $0.9 \mathrm{~kb}$ of the ORF with a 1.1-kb TRP1 fragment. Disrupted alleles were confirmed by PCR analysis. M eiosis-specific expression of a hyperstabilized SIC1 was achieved by fusing the mutant SIC1 ORF (Verma et al. 1997) to the IME2 promoter and integrating the construct at the URA 3 locus. cdc28-4 was introduced into the SK 1 strain background from BF264-15Du by backcrossing eight times with DSY 1030 a MATa derivative of DSY 1089. Three copies of an HA epitope were introduced into the carboxy-terminal of CLB5 by site-directed mutagenesis The tagged version of CLB5 was used to replace the wild-type CLB5 in both MATa and MAT $\alpha$ strains, which were then mated to produce a homozygous dipl oid DSY 1000 . All strains were grown and maintained on rich YEPD medium or synthetic medium at $30^{\circ} \mathrm{C}$ (Rose et al. 1990). Sporulation experiments were performed essentially as described (Padmore et al. 1991). Strains were initially grown in rich glycerol medium (YEPG) to select for mitochondrial function and then pregrown for $12 \mathrm{hr}$ in rich acetate medium (YEPA), washed once with sporulation medium (SPM ) and then inoculated into SPM and incubated at $30^{\circ} \mathrm{C}$ with vigorous agitation. SPM used in this study is $1 \%$ potassium acetate supplemented with $0.0005 \%$ arginine, leucine, tryptophan, and uracil. For experiments shown in Figures 1, 4A, and 5, $B-D$, homogeneous populations of $G_{1}$ phase cells grown in YEPA were isolated by centrifugual el utriation (Stuart and Wittenberg 1995) and then inoculated into sporulation medium. Cell viability was determined by a return to growth procedure (Esposito and Esposito 1974). Samples of cells from sporulating cultures were withdrawn at the indicated time points, diluted, and plated in duplicate on rich YEPD plates in the absence of any drugs or inhibitors. Colonies were counted after the plates had been incubated for 2 to 3 days at $30^{\circ} \mathrm{C}$.

\section{$\gamma$ irradiation}

Cultures pregrown to late log phase in YEPA were harvested, washed in SPM, and resuspended in SPM for $2 \mathrm{hr}$ at $30^{\circ} \mathrm{C}$. The cultures were then cooled on ice and divided in half. Half of each culture remained on ice while the other half, also on ice, was exposed to $\gamma$ radiation until a dose of $200 \mathrm{gy}$ had been administered. Both irradiated and nonirradiated cells were then resuspended in SPM and samples were withdrawn the indicated intervals and fixed in $70 \%$ ethanol for staining with DAPI, or diluted and plated to determine viability.

\section{Western blotting, immunoprecipitation, and kinase assays}

Protein extracts for Western blot analysis were prepared as described (Grandin and Reed 1993). One hundred-microgram samples were electrophoresesd through $10 \%$ gels and then transferred to nylon membrane and probed with monoclonal anti HA antibody from BABCO (1:10,000), and polyclonal anti $\mathrm{Cdc} 28$ antibody. Assay for $\mathrm{Clb5}$ associated $\mathrm{HI}$ kinase activity was performed essentially as described (Grandin and Reed 1993). Clb5HA was immunoprecipitated from $1 \mathrm{mg}$ of extract by addition of anti-HA antibody that had been conjugated to sepharose beads. After $1 \mathrm{hr}$ at $4^{\circ} \mathrm{C}$, anti $\mathrm{HA}$ beads were collected, washed three times with extraction buffer, then once with low salt buffer, the beads were then divided into two portions. One portion was assayed for $\mathrm{HI}$ kinase activity in a $10 \mu \mathrm{l}$ of reaction as described (Verma et al. 1997) and the other portion was mixed with sample buffer and analyzed by Western blot for the presence of $\mathrm{Clb5HA}$ and $\mathrm{Cdc} 28$. Histone $\mathrm{H} 1$ kinase activity was quantitated by scanning the dried gel in a Molecular Dynamics Phosphorlmager.

\section{Analysis of DNA content}

Samples of cells taken during sporulation were fixed in $70 \%$ ethanol overnight. After rehydration in $50 \mathrm{~mm}$ Tris- $\mathrm{HCl}(\mathrm{pH}$ 7.5), the samples were digested first with RN ase $A$ and then briefly with pepsin. Finally the cells were stained overnight in propidium iodide $(50 \mu \mathrm{g} / \mathrm{ml})$. DNA content of the propidium iodide stained cells was then determined by FACS with a Becton Dickinson FACSCAN (Epstein and Cross 1992).

\section{Cytology}

Sporulation frequency was determined by counting asci visualized by light microscopy. DNA was stained with propidium iodide or with DAPI and visualized by fluorescence microscopy. For determination of progression through meiosis, cells that contained two or more DAPI staining chromosomal masses were scored as being post-MI. SPBs and meiotic spindles were analyzed by fluorescence microscopy of GFP-N uf2 (Kahana et al. 1995) or GFP-Tub1 (Straight et al. 1997), respectively.

\section{Analysis of gene expression}

RNA was isolated from samples of sporulating cultures as described (Stuart and Wittenberg 1994). Northern blot analysis was performed by use of standard methods (Rose et al. 1990).

\section{Acknowledgments}

We thank Aaron Mitchell, Ted Weinert, Rati Verma, and Ray Deshaies for plasmids and strains used in this study. We also offer special thanks to M arisel a Guaderrama for technical assistance and to Ted Weinert, Yona Kassir, and members of the laboratories of C. Wittenberg, P. Russell, and S. Reed for hel pful discussions. D.S. is a Special Fellow of the Leukemia Society of America. This work was supported by U.S. Public Health Service grant GM 46006 and GM 43487 to C.W.

The publication costs of this article were defrayed in part by payment of page charges. This article must therefore be hereby marked "advertisement" in accordance with 18 USC section 1734 solely to indicate this fact.

\section{References}

Budd, M.E., K.D. Wittrup, J.E. Bailey, and J.L. Campbell. 1989. DNA polymerase I is required for premeiotic DNA replication and sporulation but not for X-ray repair in Saccharomyces cerevisiae. Mol. Cell. Biol. 9: 365-376.

Chu, S. and I. Herskowitz. 1998. Gametogenesis in yeast is regulated by a transcriptional cascade dependent on $\mathrm{N} \mathrm{dt80}$. Mol. Cell. 1: 685-696.

Collins, I. and C.S. N ewlon. 1994. Chromosomal DNA replication initiates at the same origins in meiosis and mitosis. Mol. Cell. Biol. 14: 3524-3534.

Dahmann, C. and B. Futcher. 1995. Special ization of B-type cyclins for mitosis or meiosis in S. cerevisiae. Genetics 140: 957-963.

Diffley, J.F.X., J.H. Cocker, S.J. Dowell, and A. Rowley. 1994. Two steps in the assembly of complexes at yeast replication origins in vivo. Cell 78: 303-316. 
Dunphy, W.G., L. Brizuela, D. Beach, and J. N ewport. 1988. The Xenopus cdc2 protein is a component of M PF, a cytoplasmic regulator of mitosis. Cell 54: 423-431.

Edgar, B.A., F. Sprenger, R.J. Duronio, P. Leopold, and P. O'Farrell. 1994. Distinct molecular mechanisms regulate cell cycle timing at successive stages of Drosophila embryogenesis. Genes \& Dev. 8: 440-452.

Elsasser, S., F. Lou, B. Wang, J. Campbell, and A. Jong. 1996. Interaction between yeast Cdc6 protein and B-type cyclin/ Cdc28 kinases. Mol. Biol. Cell. 7: 1723-1735.

Epstein, C.B. and F.R. Cross. 1992. CLB5: A novel B cyclin from budding yeast with a role in S phase. Genes \& Dev. 6: 16951706.

Esposito, M.S. and R.E. Esposito. 1974. Genetic recombination and commitment to meiosis in Saccharomyces cerevisiae. Proc. Nat. Acad. Sci. 71: 3172-3176.

Fitch, I., C. Dahman, U. Surana, A. Amon, K. Nasmyth, L. Goetsch, B. Byers, and B. Futcher. 1992. Characterization of four B-type cyclin genes of the budding yeast Saccharomyces cerevisiae. Mol. Biol. Cell. 3: 805-818.

Gautier, J., C. N orbury, M. Lohka, P. N urse, and J. Maller. 1988. Purified maturation-promoting factor contains the product of a Xenopus homolog of the fission yeast cell cycle control gene cdc2 ${ }^{+}$. Cell 54: 433-439.

Gautier, J., J. M inshull, M. Lohka, M. Glotzer, T. Hunt, and J.L. Maller. 1990. Cyclin is a component of maturation-promoting factor from Xenopus. Cell 60: 487-494.

Grandin, N. and S.I. Reed. 1993. Differential function and expression of Saccharomyces cerevisiae B-type cyclins in mitosis and meiosis. Mol. Cell. Biol. 13: 2113-2125.

Hartwell, L.H. 1974. Saccharomyces cerevisiae cell cycle. Bacteriol. Rev. 38: 164-198.

Hartwell, L.H. and T.A. Weinert. 1989. Checkpoints: Controls that ensure the order of cell cycle events. Science 246: 629634.

Honigberg, S.M. and R.E. Esposito. 1994. Reversal of cell determination in yeast meiosis: Post commitment arrest allows return to mitotic growth. Proc. Natl. Acad. Sci. 91: 6559-6563.

lino, Y., Y. Hiramine, and M. Yamamoto. 1995. The role of cdc2 and other genes in meiosis in Schizosaccharomyces pombe. Genetics 140: 1235-1245.

Johnston, L.H., A.L. Johnson, and J.C. Game. 1982. The effect of the cdc9 mutation on premei otic DN A synthesis in the yeast Saccharomyces cerevisiae. Exp. Cell Res. 141: 63-69.

Kahana, J.A., B.J. Schnapp, and P.A. Silver. 1995. Kinetics of spindle pole body separation in budding yeast. Proc. Natl. Acad. Sci. 92: 9707-9711.

Kane, S.M. and R. Roth. 1974. Carbohydrate metabolism during ascospore development in yeast. J. Bacteriol. 118: 8-14.

Kleckner, N. 1996. Meiosis: How could it work? Proc. Natl. Acad. Sci. 93: 8167-8174.

Kuhne, C. and P. Linder. 1993. A pair of B-type cyclins from Saccharomyces cerevisiae that function early in the cell cycle. EMBO J. 12: 3437-3447.

Kupiec, M., B. Byers, R.E. Esposito, and A.P. Mitchell. 1997. Meiosis and sporulation in Saccharomyces cerevisiae. In Molecular and cellular biology of the yeast Saccharomyces. Cell cycle and cell biology (ed. J.R. Pringle, J.R. Broach, and E.W. Jones), pp. 889-1036. Cold Spring Harbor Laboratory Press, Cold Spring Harbor, NY.

Lew, D.J., T. Weinert, and J.R. Pringle. 1997. Cell cycle control in Saccharomyces cerevisiae. In The molecular and cellular biology of the yeast Saccharomyces cell cycle and cell biology (ed. J.R. Pringle, J.R. Broach, and E.W. Jones), pp. 607695. Cold Spring Harbor Laboratory Press, Cold Spring Harbor, NY.
Li, J.J. and R.J. Deshaies. 1993. Exercising self restraint: Discouraging illicit acts of $S$ and $M$ in eukaryotes. Cell 74: 223226.

Li, X. and R.B. Nicklas. 1995. Mitotic forces control a cell cycle checkpoint. Nature 373: 630-632.

$\mathrm{Li}, \mathrm{X}$. and M. Cai. 1997. Inactivation of the cyclin-dependent kinase Cdc28 abrogates cell cycle arrest induced by DNA damage and disassembly of the mitotic spindle in Saccharomyces cerevisiae. Mol. Cell. Biol. 17: 2723-2734.

Lohka, M.J., M.K. Hayes, and J.L. Maller. 1988. Purification of maturation-promoting factor, an intracellular regulator of early mitotic events. Proc. Natl. Acad. Sci. 85: 3009-3013.

Lydall, D., Y. Nikolsky, D.K. Bishop, and T. Weinert. 1996. A meiotic recombination checkpoint controlled by mitotic checkpoint genes. Nature 383: 840-843.

Masui, Y. and C.L. Markert. 1971. Cytoplasmic control of nuclear behavior during meiotic maturation of frog oocytes. J. Exp. Zool. 177: 129-146.

McKim, K.S. and R.S. Hawley. 1995. Chromosomal control of meiotic cell division. Science 270: 1595-1600.

Mitchell, A.P. 1994. Control of meiotic gene expression in Saccharomyces cerevisiae. Microbiol. Rev. 58: 56-70.

$\mathrm{N}$ asmyth, K. 1993. Control of the yeast cell cycle by the $\mathrm{Cdc} 28$ protein kinase. Curr. Opin. Cell Biol. 5: 166-179.

N ewport, J.W. and M.W. Kirschner. 1984. Regulation of the cell cycle during early Xenopus development. Cell 37: 741-742.

O'Farrell, P.H., B.A. Edgar, D. Lakich, and C.F. Lehner. 1989. Directing cell division during development. Science 246: 635-640.

Orr-Weaver, T.L. 1994. Devel opmental modification of the Drosophila cell cycle. Trends Genet. 10: 321-327.

Padmore, R., L. Cao, and N . Kleckner. 1991. Temporal comparison of recombination and synaptonemal complex formation during meiosis in Saccharomyces cerevisiae. Cell 66: 12391256.

Piatti, S., C. Lengauer, and K. N asmyth. 1995. Cdc6 is an unstable protein whose de novo synthesis in $\mathrm{Gl}$ is important for the onset of S phase and for preventing a "reductional" anaphase in the budding yeast Saccharomyces cerevisiae. EMBO J. 14: 3788-3799.

Piatti, S., T. Bohm, J.H. Cocker, J.F.X. Diffley, and K. N asmyth. 1996. Activation of S-phase promoting CDKs in late Gl defines a "point of no return" after which Cdc6 synthesis cannot promote DNA replication in yeast. Genes \& Dev. 10: 1516-1531.

Reed, S.I. 1992. The role of p34 kinases in the G1 to S-phase transition. Annu. Rev. Cell Biol. 8: 529-561.

Reed, S.I., J.A. Hadwiger, and A.T. Lorincz. 1985. Protein kinase activity associated with the product of the yeast cell division cycle gene CDC28. Proc. Natl. Acad. Sci. 82: 4055-4059.

Richardson, H.E., C. Wittenberg, F.R. Cross, and S.I. Reed. 1989. An essential $\mathrm{G} 1$ function for cyclin-like proteins in yeast. Cell 59: 1127-1133.

Richardson, H.E., D.J. Lew, M. Henze, K. Sugimoto, and S.I. Reed. 1992. Cyclin-B homologs in Saccharomyces cerevisiae function in S phase and in G2. Genes \& Dev. 6: 2021-2034.

Roeder, G.S. 1997. M eiotic chromosomes: It takes two to tango. Genes \& Dev. 11: 2600-2621.

Rose, D. and C. Holm. 1993. Meiosis specific arrest revealed in DNA topoisomerase II mutants. Mol. Cell. Biol. 13: 34453455.

Rose, M.D., F. Winston, and P. Heiter. 1990. Methods in yeast genetics. A laboratory course manual. Cold Spring Harbor Laboratory Press, Cold Spring Harbor, NY.

Schild, D. and B. Byers. 1978. M ei otic effects of DNA-defective cell division cycle mutations of Saccharomyces cerevisiae. 
Chromosoma 70: 109-130.

Schwob, E. and K. N asmyth. 1993. CLB5 and CLB6, a new pair of $B$ cyclins involved in DN A replication in Saccharomyces cerevisiae. Genes \& Dev. 7: 1160-1175.

Schwob, E., T. Boehm, M.D. Mendenhall, and K. N asmyth. 1994. The B-type cyclin kinase inhibitor $\mathrm{p} 40^{\mathrm{SIC} 1}$ controls the G1/S transition in Saccharomyces cerevisiae. Cell 79: 233244.

Shuster, E.O. and B. Byers. 1989. Pachytene arrest and other meiotic effects of the start mutations in Saccharomyces cerevisiae. Genetics 123: 29-43.

Simchen, G., D. Idar, and Y. Kassir. 1976. Recombination and hydroxyurea inhibition of DNA synthesis in yeast meiosis. Mol. \& Gen. Genet. 144: 21-27.

Straight, A.F., W.F. Marshall, J.W. Sedat, and A.W. Murray. 1997. Mitosis in living budding yeast: Anaphase $A$ but no metaphase plate. Science 277: 574-578.

Stuart, D. and C. Wittenberg. 1994. Cell cycle-dependent transcription of CLN 2 is conferred by multiple distinct cis-acting regulatory elements. Mol. Cell. Biol. 14: 4788-4801.

- - . 1995. CLN 3, not positive feedback, determines the timing of CLN 2 transcription in cycling cells. Genes \& Dev. 9: 2780-2794.

Stueland, C.S., D.J. Lew, and S.I. Reed. 1993. Full activation of p34 ${ }^{\mathrm{CDC} 28}$ histone $\mathrm{H} 1$ kinase activity is unable to promote entry into mitosis in checkpoint-arrested cells of the yeast Saccharomyces cerevisiae. Mol. Cell. Biol. 13: 3744-3755.

Su, S.S.Y. and A.P. M itchell. 1993. Identification of functionally related genes that stimulate early meiotic gene expression in yeast. Genetics 133: 67-77.

Su, T.T., S.D. Campbell, and P.H. O'Farrell. 1998. The cell cycle program in germ cells of the Drosophila embryo. Dev. Biol. 196: $160-170$.

Tavormina, P.A., Y. Wang, and D.J. Burke. 1997. Differential requirements for DNA replication in the activation of $\mathrm{mi}$ totic checkpoints in Saccharomyces cerevisiae. Mol. Cell. Biol. 17: 3315-3322.

Thorne, L.W. and B. Byers. 1993. Stage specific effects of Xirradiation on yeast meiosis. Genetics 134: 29-42.

Toyn, J.H., L. Johnson, and L.H. Johnston. 1995. Segregation of unreplicated chromosomes in Saccharomyces cerevisiae re veals a novel G1/M-phase checkpoint. Mol. Cell. Biol. 15: 5312-5321.

Tsui, K., L. Simon, and D. Norris. 1997. Progression into the first meiotic division is sensitive to histone $\mathrm{H} 2 \mathrm{~A}-\mathrm{H} 2 \mathrm{~B}$ dimer concentration in Saccharomyces cerevisiae. Genetics 145: 647-659.

Verma, R., S. Annan, M.J. Huddleston, S.A. Carr, G. Reynard, and R.J. Deshaies. 1997. Phosphorylation of Siclp by $\mathrm{G}_{1} \mathrm{Cdk}$ required for its degradation and entry into $S$ phase. Science 278: $455-460$.

Wach, A., R. Brachat, R. Pohlmann, and P. Philippsen. 1994. $\mathrm{N}$ ew heterologous modules for classical or PCR-based gene disruptions in Saccharomyces cerevisiae. Yeast 10: 17931808.

Weber, L. and B. Byers. 1992. A RAD9-dependent checkpoint blocks meiosis of cdc13 yeast cells. Genetics 131: 55-63.

Weiner, B.M. and N. Kleckner. 1994. Chromosome pairing via multiple interstitial interactions before and during meiosis in yeast. Cell 77: 977-991.

Weinert, T., G.L. Kiser, and L.H. Hartwell. 1994. Mitotic checkpoint genes in budding yeast and the dependence of mitosis on DNA replication and repair. Genes \& Dev. 8: 652-665.

Xu, L., M. Ajimura, R. Padmore, C. Klein, and N. Kleckner. 1995. NDT80, a meiosis specific gene required for exit from pachytene in Saccharomyces cerevisiae. Mol. Cell. Biol. 15:
$6572-6581$.

Xu, L., B.M. Weiner, and N. Kleckner. 1997. Meiotic cells monitor the status of the interhomolog recombination complex. Genes \& Dev. 11: 106-118.

Zamb, T.J. and R. Roth. 1977. Role of mitotic replication genes in chromosome duplication during meiosis. Proc. Nat. Acad. Sci. 74: 3951-3955.

Zou, L. and B. Stillman. 1998. Formation of a preinitiation complex by S-phase cyclin CDK dependent loading of Cdc45p onto chromatin. Science 280: 593-596. 


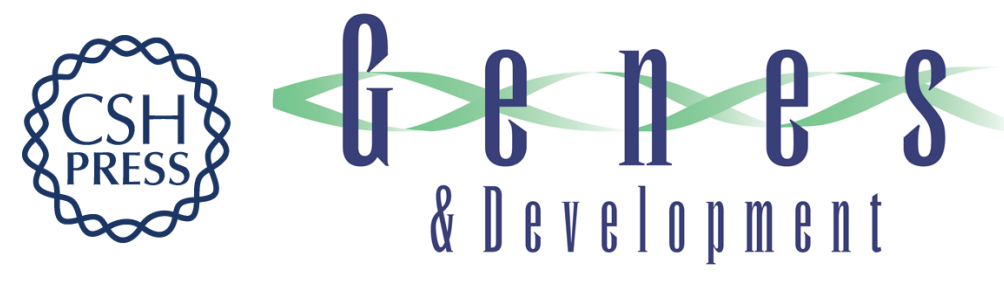

\section{CLB5 and CLB6 are required for premeiotic DNA replication and activation of the meiotic S/M checkpoint}

David Stuart and Curt Wittenberg

Genes Dev. 1998, 12:

Access the most recent version at doi:10.1101/gad.12.17.2698

References This article cites 67 articles, 44 of which can be accessed free at: http://genesdev.cshlp.org/content/12/17/2698.full.html\#ref-list-1

License

Email Alerting

Receive free email alerts when new articles cite this article - sign up in the box at the top Service right corner of the article or click here.

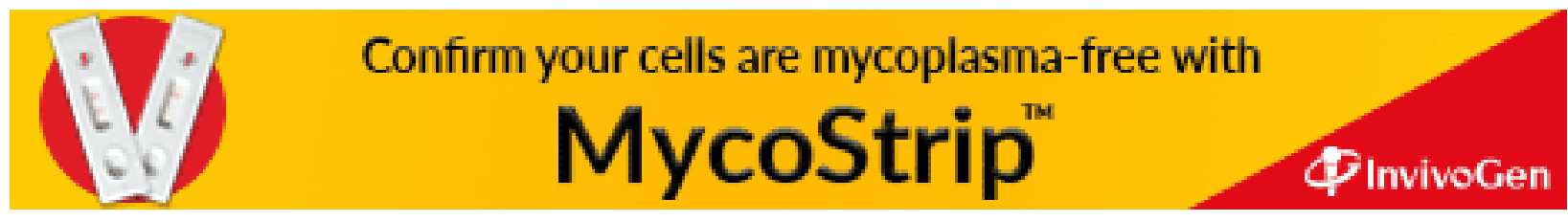

